\title{
BIOPHILIC URBAN DEVELOPMENTS FOLLOWING DYNAMIC FLOWS OF TREE-SHAPED ARCHITECTURES
}

\author{
Eleni Tracada \\ University of Derby, College of Engineering and Technology, Department of Mechanical Engineering and Built \\ Environment, Markeaton Street, Derby DE22 3AW, United Kingdom \\ Email: E.Tracada@derby.ac.uk
}

\begin{abstract}
Latest theories and practices in Biophilic designs of the urban space regard the urban fabric as being composed of several interrelated layers of energetic structure influencing each other in a non-linear manner primarily. The interaction between two or more interfaces of the urban space layers evolves into new and non-predictable properties. Evolution and creation of new boundaries/interfaces follows laws related to fractal growth; most of the times this particular evolution is defined by laws of physics, such as Thermodynamics and Constructal Law. Designs that do not follow these laws may produce anti-natural and hostile environments, which do not fit into human beings' evolution, and thus, fail to enhance life by all means.

The author of this paper should like to illustrate how new developments of urbanism worldwide currently work upon conceptual and town planning models based not only upon cutting-edge technology, but also upon natural laws and patterns of life and human behaviours strictly related to flaws and movement dictated by natural phenomena. When abrupt interruption of the urban structure has occurred, a consequent design solution does not even guarantee flowing and freedom to morph. It is impossible to create harmonic designs which naturally "unite the animate with the inanimate", as Adrian Bejan and Sylvie Lorente affirm, whenever urban sprawl fails to encompass Biophilic solutions related to tree-shaped architectures. The author argues that Constructal invasion into the urban space "as fundamental problems of access to flow: volume to point, area to point, line to point, and the respective reverse flow directions" can only guarantee high standard quality of life in either contemporary or future cities developments.
\end{abstract}

Keywords: Biophilic design, Human behaviour, Thermodynamics, Constructal law, Healthy cities.

\section{INTRODUCTION}

For many years as a student of architecture at first and later as an architect, the author had the opportunity to observe and investigate on the historical evolution of specific areas inside the city of Florence, Italy. A number of interesting elements emerged from that research which offered the author the opportunity to discover 'hidden' paths and agendas well preserved inside the development of special urban fabric. These strong indexical elements always enabled architecture to act as an originator of infinite solutions to a variety of public uses and demands of urban spaces.

For several centuries ongoing alterations inflicted to buildings had not managed to deprive them from specific qualities and identities at all. Entire historical blocks in urban central areas continued to preserve their positive vigour in spite the efforts of being utterly altered by negative synergies, which were solicited by wrong policies and at the wrong times of history. Thus, rundown and abandoned areas had included for centuries these wonderful 'hidden seeds' which later managed to emerge and recreate lost links. These hidden elements and, especially several special historical paths of human flow, acted as positive regeneration cells which guaranteed further positive sprawl of the city.
In contemporary Florence some architectural complexes which had changed through time from positive to extremely negative spaces finally succeeded in re-acquiring their original qualities and character of hospitality and culture. Buildings and urban fabric which had been brutally transformed into seclusion places, such as the 19th and 20th century prison complexes, were recently freed from elements of spatial bewilderment and impediment of free human flows; architecture and the urban space acquired again their primordial values dictated by profound social synergies.

During her studies in the 1980s and professional practice years in the 1990s, the author had the opportunity to engage in research with experts in urban design and studies, like Edoardo Detti, Giovanni Michelucci and many other fellow students who are also now active researchers, professionals and educators. Her studies and research in the historical evolution of the built environment reinforced her ideas and, therefore her teaching activities promoted more research; important findings and new collaborations with experts in new disciplines, such as Biophilic Design and Biourbanism had further supported her initial research.

Thus, the author's conclusions in relation to the natural genesis of the built environment could be summarised by the points below. According to her analysis and observation of the urban sprawl considered as natural growth, the entire built and unbuilt environment is the end result of: 
$\circ$ Lines, grids and energetic geometries interweaving

- Line performance and actions/emergence of flows and spaces inflicted and affected by these flows

- A complex system of manifestations of life genesis and growth.

All these points above are further explained in the diagram shown in Fig. 1, where a core of energetic flows surpasses restrictions and boundaries and finally manages to burst out into infinite actions in order to design and develop more spaces.

$$
\begin{gathered}
\text { Act } \\
\text { Ek }(\mathrm{c}) \text {-is } \\
\text { Line pointing +piercing+penetrating into a space } \\
\text { Explosion of cosmic lines = Space/Ch-oros } \\
\wedge \\
\text { Core of energetic flows }
\end{gathered}
$$

Figure 1. Line Performance Act [1]

Spaces are created by geometries and space for the actor/artist/architect becomes their real obsession. At all times, artists, designers and architects have been fascinated by geometries generated by the pathlines' mystical dynamism which is able to create primordial shapes, cells and complex forms. Several times the author affirmed that 'form comes to the real world when line moves along a creative performing process. There is always an everlasting performance act of lines which penetrates space and defines it as a telic art.' [2]

Space is without doubt related to everything concerning human life. Space into vocabulary has been related to time and duration as well, whereas space denoting area or extension is a linear distance or interval between two or more points or objects. An exceptionally interesting aspect of the term space can be found in the ancient Greek word ch-òros, which contains the root òros (= edge, boundary, but also rule). Thus, space as ch-òros means spatial expansion of human activity between boundaries and beyond; that expansion is not necessarily linear. From the edges/interfaces of a space, a new line, or better a formation of tree-form architectures acts and moves as a piercing element towards the surrounding natural and artificial environments; this is often a manifestation of human movement because of energetic changes in behaviours. Act originates from Ancient Greek 'ak-is', formed by the Ancient Arian root 'Ak' or 'Ac' which means 'a piercing item', such as a sword. According to the author, act means everlasting movement and behaviour of human beings and artificially created pathlines interacting at the same time as an indicator of performances and urban rituals. [1]

Many times the author was captivated by two-dimensional drawings or paintings by artists, like, for example, Paul Klee's line growth drawings and linear tensions and nodes as shown in Paul Klee's 'The thinking eye: Notebooks'-Volume 1 and included in the author's unpublished dissertation for a Masters in Interior and 3D Design in the Manchester Metropolitan University in 1996. [3] The author analysed and discussed Paul Klee's work in her dissertation, because she had found plentiful evidence of natural growth of spaces triggered by energetic lines to form $2 \mathrm{D}$ and $3 \mathrm{D}$ designs (See Fig. 2 \& Fig. 3).

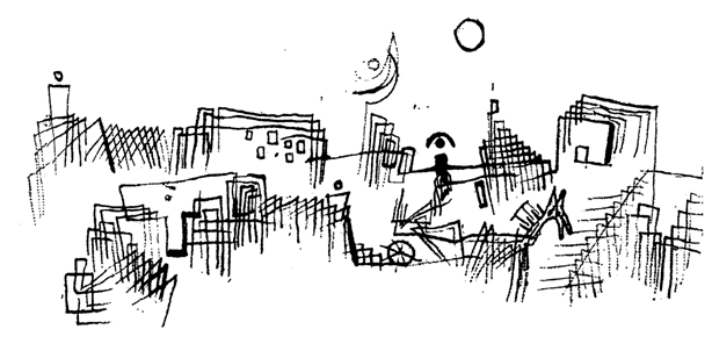

Figure 2. Undulating Wave-lines: Drama in 'Difficult Journey Through' by Paul Klee (1927)

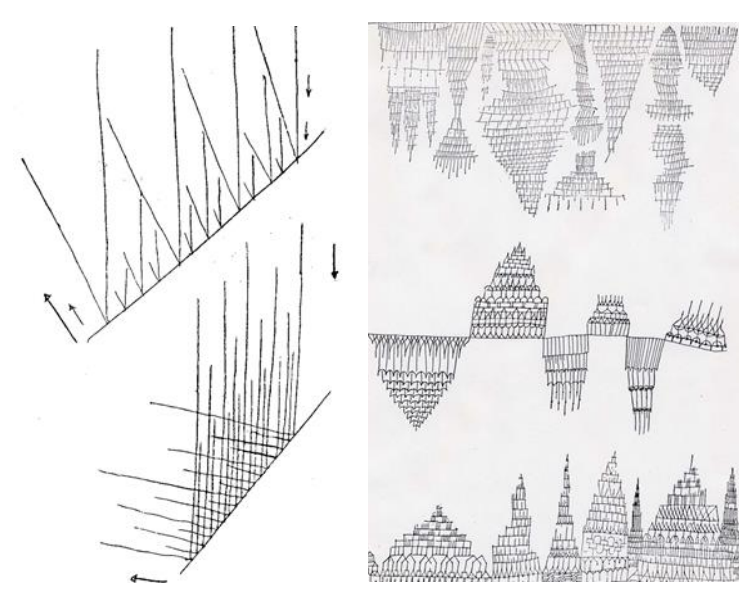

Figure 3. 'Deflection through an angle' and 'Increase and decrease' in Paul Klee, The thinking eye: Notebooks-Volume $1[3]$

In fact in Fig. 3 (above), we can see clearly the impact of flows against boundaries/interfaces and the new explosions of increasing lines. Thus, the author has been convinced that movements and flows are vital part in generating new urban spaces; she started researching more on cases of new growth of urban fabric and emerging architectures following the rules of social historical indexes, as 'hidden agenda' inside that urban sprawl. Personal research since the 1990s based upon field work in Florence and other Italian cities led to the analysis of very interesting case studies and phenomena encouraging ongoing and harmonious urban sprawl. For example, a fine case of concealed energetic pathlines forming a hidden, unremitting agenda for future urban growth was discovered during analysis of maps of the central area of Florence; a continuity of pathlines had been set not only as an originator of 2D formations of streets and piazzas, but also as a motivator of $3 \mathrm{D}$ explosions of tree-architectures by means of arrangements of internal courtyards and porticos according to continuous and uninterrupted energetic human flows (treeform paths). The author discovered that the continuity of all grids and expansion had been preserved for several centuries and until present time. The oldest piece of evidence of these powerful pathlines can be found in Stefano Buonsignori's map of Florence (See Fig. 4) in which Renaissance urban sprawl is clearly shown and also the first signs of urban patterns and fractal growth. 


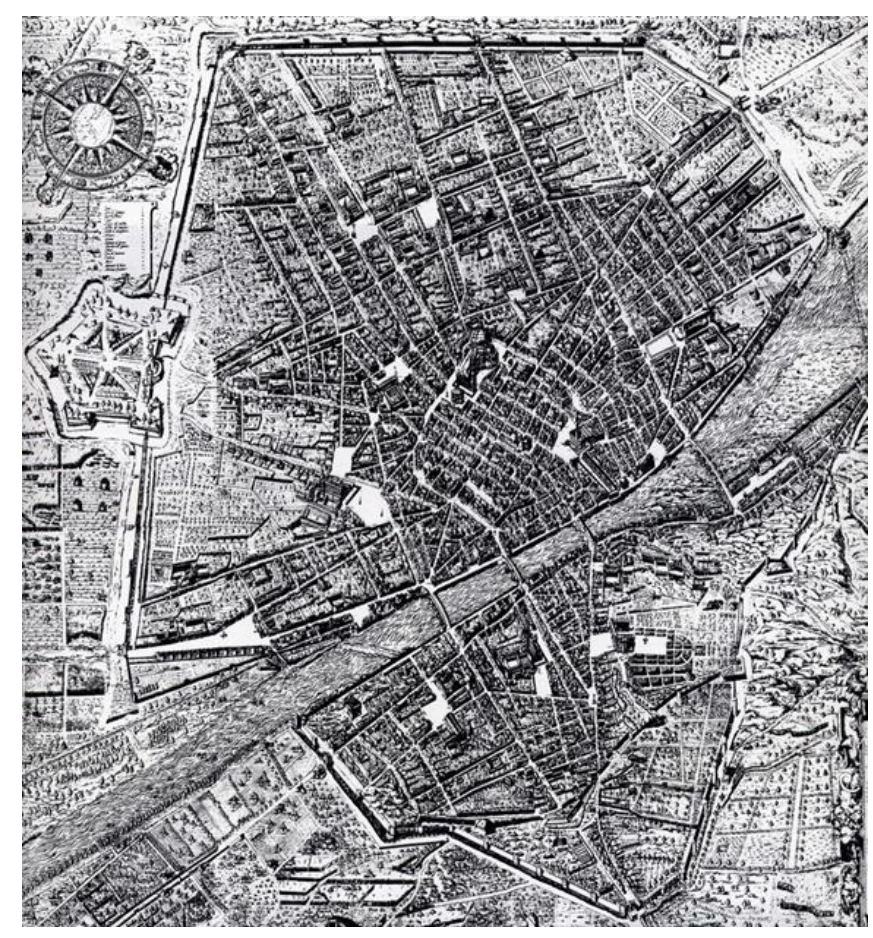

Figure 4. Stefano Buonsignori's map of Florence (1584) [3]

\section{CONSTRUCTAL LAW AND BIOURBANISM}

Since 2011 the author has been involved with research and educational projects, such as specialist summerschools, with other members of the scientific committee of the International Society of Biourbanism. New methods of designing or revitalising cities today follow new forms of Urbanism, such as Biourbanism. Biourbanism (and in general Biophilic design) introduces new conceptual and planning models for a new kind of city, which values social and economic regeneration of the built environment through developments of healthy communities. As a discipline, it combines technical aspects, such as zero-emission, energy efficiency, information technology, etc. and the promotion of social sustainability and human wellbeing. It endorses principles of geometrical coherence and new urban policies to promote urban revitalization by ensuring that man-made changes do not have harmful effects to humans. [4]

Green city standards may originate inside the designs for each building and carry on affecting either unbuilt spaces surrounding buildings or even complex infrastructural networks and connections of buildings and people. New exciting developments recently, such as fractals, complexity theory, evolutionary biology and artificial intelligence are interrelated and constantly stimulate interaction between human beings and the surrounding built and natural environment. [5]

Dr Antonio Caperna and the author collaborate to write documents related to Biourbanism; they have often produced important conference and journal papers. In EDRA44 in Providence, USA, Dr Stefano Serafini and the author organised a special workshop on Biourbanism with the title of Thermodynamics of Architecture and Urban Fabric: Designing and Reshaping Cityscapes by Laws of Nature; the authors argued that the new discipline as a combination of sciences and theories and practices should be considered as 'art of making a healthy city for healthy citizens.' The authors affirmed that 'how human neurophysiology reacts to the organization and the forms of space is the first step to produce undeniably sustainable new design for the 21 st century.' [6]

During important conferences the author in collaboration with other experts has affirmed that natural forms are ruled by mathematics and physics and human beings are part of this natural world as well. Thus, by creating Biophilic designs today, we are not only able to intervene to both natural and built environment, but also to human bios (= active human lives) of the people.

For example in a couple of events, both Dr Serafini and the author affirmed that natural forms are dictated by mathematics and physics. The presence of Fibonacci patterns is universal in nature, from galaxies to seashells, from magnetized droplets in a viscous medium to the organization of florets in plants (as shown in the figure for sunflowers, see Fig. 5). Moreover, the numbers of such spirals (clockwise versus counter clockwise) are typically Fibonacci numbers (21 and 34 respectively).

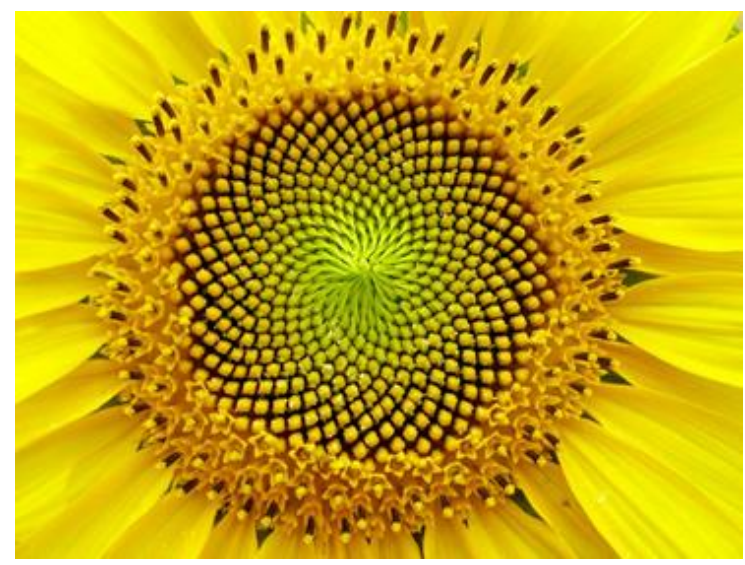

Figure 5. Sunflower pattern in http://en.wikipedia.org/wiki/File:Red_sunflower.jpg 
Biourbanism considers the city as a living organism; it studies it within the frame of Integrated Systems Sciences and the last advancements of Life Sciences, such as:

- Laws of form and Self-organization in evolution

- Constructal Law

- Morphogenetic processes.

As Dr Antonio Caperna puts it, 'Biourbanism recognizes optimal forms defined at different scales (from the purely physiological up to the ecological levels) which, through morphogenetic processes, guarantee an optimum of systemic efficiency and for the quality of life of the inhabitants. A design that does not follow these laws produces anti-natural, hostile environments, which do not fit into an individual's evolution, and thus fail to enhance life in any way." [4] According to several experts, some critical questions that designers should not avoid during design processes and practices could be:

- Why do some built forms resemble biological forms?

- What types of built forms correspond more closely to biological prototypes?

- Are human beings predisposed to like and feel comfortable with certain types of forms?

- Are human beings also predisposed to build certain types of forms?

○ Is it worthwhile mimicking biological forms in what we build?

- Do we gain more than just aesthetic pleasure -- such as physical and psychological benefits, for example -- from an environment that captures the essence of biological structure?

- Can we damage ourselves by living in and around forms that contradict biological forms?

$\circ \quad$ Do we really understand biological structure well enough to mimic anything other than its superficial appearance?

\section{CONSTRUCTAL LAW AND FRACTAL CITIES}

The human sensory systems have evolved to respond to natural geometries of fractals, colours, scaling, and symmetries; they are fine-tuned to detect pathologies of our body, signed by departure from natural geometries. Human beings require contact with the geometry of biological structure; social and mental health deteriorates in nature-less surroundings. The author studied and often considered Christopher Alexander's Pattern Language and principles during her research and teaching efforts as well. She affirmed that: 'Christopher Alexander (architect and urban designer) talks about patterns/codes and visual language and says that designers and architects should not only be able to write and read a language, but also be able to develop it further by understanding every feature of it and by giving it new meaning according to their own identity.' [7]

Also other authors, like Prof. Nikos Salingaros claim that: 'Traditional urban geometry is characterised by fractal interfaces' [8] Cities evolve their own organic/fractal form by self defining it through connectivity of people on the move in cities. [9] Thus, fractal cities' symmetries and patterns of fabric can influence human well-being. As Prof. Salingaros puts it: 'Plans, patterns, symmetry, axes, are only of secondary importance relative to the fundamental processes that generate urban space. This lends support for the irregularity of successful urban spaces.' [8] According to the same author, fractal coupling forces in mapping create lines of communication between human beings and environments.

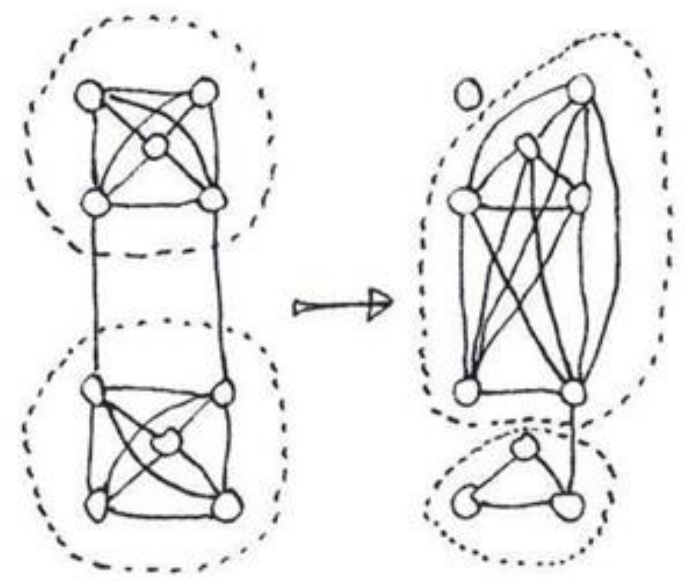

Figure 6. Two modules reorganise themselves overtime by defining new connections and new boundaries [8]

By referring to emergence and morphogenesis in architecture, nature has been re-proposed by computation and maths. Steven Johnson identifies as four principles of emergence: local interaction of neighbours, pattern recognition, feedback and indirect control [10] 'The movement from low-level rules to higher-level sophistication is what we call emergence'; and '... a higher-level pattern arising out of parallel complex interactions between local agents.' [10] 'Emergence is a classical concept in systems theory, where it denotes the principle that the global properties defining higher order systems or 'wholes' (e.g. Boundaries, organisation, control ...) can in general not to be reduced to the properties of the lower order subsystems or 'parts'. Such irreducible properties are called emergent. 'The spontaneous creation of an 'organised whole' out of a 'disordered' collection of interacting parts, as witnessed in self-organising systems in physics, chemistry, biology, sociology ... is a basic part of dynamical emergence.' [11] And Alfred North Whitehead, mathematician and philosopher, argues that: 'Process rather than substance was the fundamental constituent of the world. Nature consists of patterns of activity interacting with each other. Organisms are bundles of relationships that maintain themselves by adjusting their own behaviour in anticipation of changes to the patterns of activity around them.' [12]

For example, these principles can be easily distinguished in Otto Frei's computational morphogenesis modelling or in the evolution of urban fabric in time, as we see further.

Constructal Law has been introduced by Adrian Bejan affirming that 'design is a universal phenomenon in nature. It is physics. It happens naturally when something is flowing and it is free to morph. Design unites the animate with the inanimate.' [13] And: 'Designs are tree-shaped' [13] or as Bejan and Lorente put it about tree-shaped architectures: 'Constructal invasion of a conducting tree into a conducting body' [13] could be the basic principle of the evolution of the built environment as well. 


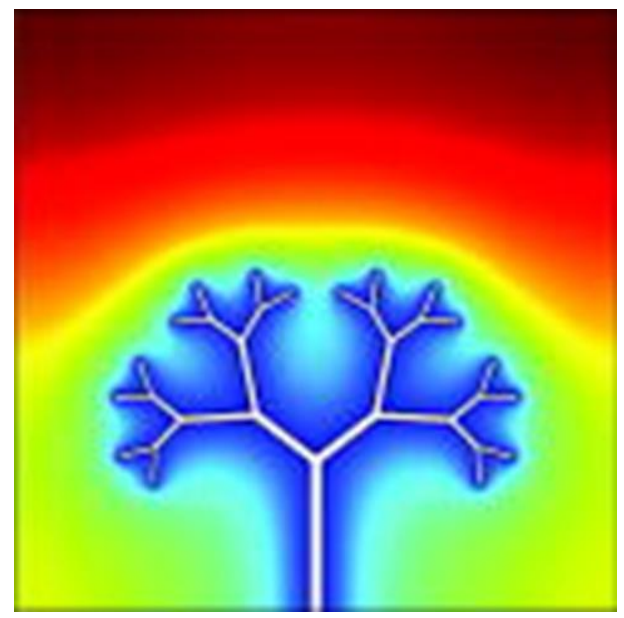

Figure 7. Tree shaped architectures from Wikipedia.

Also other authors have supported the same principles in design by affirming that: 'Life is flow: all flow systems are live systems, the animate and the inanimate.' [14]) And treeshaped architectures are thought to be: 'Design generation and evolution is a phenomenon of physics.' [15] During recent years the author has started teaching the theory of the vegetation design and the flow of water stresses to her students in her modules Designing Environments and Research and Urban Design (Levels 6 \& 7) alongside theories of fractal evolution; the students have consider these stresses as new models for designing modern urban spaces and architecture. Some students have applied these theories especially on corrections of plans of regeneration of urban fabric or corrections during the integration of infrastructure in the built environment, such as the case study and model presented in the paper 'Complexity and Biourbanism: Thermodynamical Architectural and Urban Models integrated in Modern Geographic Mapping' during the Conference of Theoretical Currents II in Lincoln, UK. [16]

\section{CONCLUSIONS}

The author is aware that flows of people and urban behaviours follow mostly vegetation design and flows of water and stresses; it is obvious that 'the tree must be selfhealing to survive strong winds ... it must have the ability to bulk up in places where stresses are higher. It must be able to distribute its stresses as uniformly as possible, so that all its fibres work hard towards the continued survival of the mechanical structure.' [17] Stresses could be always distributed uniformly along pathlines of urban sprawl with attention and care for tree-shaped harmonious expansions. However the author and her students should like to be able to understand and apply some more ideas and principles of Constructal law and especially how the system of Earth functions could be possibly fit to the built environment and urban space designs and, what could be its maximum 'power generation' or 'minimum dissipation' in relation to maximum and minimum allowed to stresses to nodal points of new expansions. Would it be a machine in reality, what we usually consider as free flow design?

\section{ACKNOWLEDGMENT}

The author should like to thank her colleagues in the International Society of Biourbanism for their continuous support and especially her students for their useful discussions and issues raised during lectures and workshops.

\section{REFERENCES}

1. Tracada, E., Caperna, A., "A new paradigm for deep sustainability: Biourbanism," Proceedings of the First International Conference \& Exhibition on Application of Efficient and Renewable Energy Technologies in low cost buildings and Construction, 16-18 September, Ankara-Turkey, Gazi University, 367-381, 2013.

2. Tracada, E., Chapter 5: Design Codes and Design Language, Design-Pedagogy-Research: Leeds 2007, Huddersfield, Jeremy Mills Publishing \& Leeds College of Art and Design, 37-49, 2008.

3. Tracada, E., "Line performance act," Dissertation (unpublished), Manchester Metropolitan University, UK, 1996.

4. Tracada, E., Caperna, A., "Biourbanism for a healthy city: Biophilia and sustainable urban theories and practices," Proceedings Vol.4: Biotechnology/Textile Technology/Fashion Technology of the International Convention on Innovations in Engineering and Technology for Sustainable Development, 3-5 September 2012, Erode District, Tamil Nadu, India, Bannari Amman Institute of Technology, FT-01 to FT09, 2012.

5. Tracada, E., "The fractal urban coherence in biourbanism: The factual elements of urban fabric," The International Journal of Architectonic, Spatial, and Environmental Design 7 (1), 1-17, 2013.

6. Caperna, A., Tracada, E., Serafini, S., "Thermodynamics of architecture and urban fabric: Designing and reshaping cityscapes by laws of nature," Workshop in EDRA44 Providence, 2013.

7. Tracada, E., "Chapter 3: Reading buildings and translating places: 'a place to...,"' Explorations in Spatiality, Leeds: University of Leeds, Spatiality in Design, 41-51, 2006.

8. Salingaros, N.A., Principles of Urban Structure, Amsterdam, Techne Press, 2005.

9. Salingaros, N.A., A Theory of Architecture, Solingen, Umbau-Verlag, 2006 \& 2008.

10. Johnson, S., Emergence, the Connected Lives of Ants, Brains, Cities and Software, Penguin Press, 2001.

11. Heylighen, F., "Self-organisation, emergence and the architecture of complexity," Proceedings of the 1st European Conference on System Science, Paris.

12. Alfred North Whitehead, A.N., The Concept of Nature, Cambridge, University Press, 1920.

13. Bejan, A., Lorente, S., "Constructal law of design and evolution: Physics, biology, technology, and society," Journal of Applied Physics, 113, 151301, 2013. DOI: 10.1063/1.4798429.

14. Basak, T., "The law of life: the bridge between Physics and Biology," Phys Life Rev (8), 249-252, 2011. DOI: 10.1016/j.plrev.2011.07.003.

15. Wang, L., "Universality of design and its evolution," Phys Life Rev (8), 257-258, 2011. DOI: 10.1016/j.plrev.2011.08.003. 
16. Tracada, E., Caperna, A., "Complexity and Biourbanism: thermodynamical architectural and urban models integrated in modern geographic mapping," Proceedings of the Theoretical Currents II, Lincoln University, Lincoln, UK, 4th-5th April 2012 (available at www.biourbanism.org), 2012.
17. Bejan, A., Lorente, S., Lee, J., "Unifying Constructal theory of tree roots, canopies and forests," Journal of Theoretical Biology, 254, 529-540, 2008. DOI: 10.1016/j.jtbi.2008.06.026. 